\title{
Deficits in central auditory processing among migraine patients
}

\author{
Somia Tawfik', Randa Amin², Sahar Ibrahim³ and Tayseer Taha Abdel Rahman ${ }^{1^{*}}$ (I)
}

\begin{abstract}
Background: Migraine is a neurological disease associated with abnormal excitability in visual, somatosensory, and motor cortex. This study aimed to verify and compare auditory processing performance in migraine patients with and without dizziness and healthy controls.

Results: Sixty subjects were divided into 3 groups: control group, twenty normal healthy subjects, and study group I (twenty subjects diagnosed with migraine) and study group II (twenty subjects diagnosed with vestibular migraine). They were evaluated using the Central Auditory Processing Questionnaire for adults, tympanometry, pure tone audiometry, Psychophysical Central Auditory Tests, including Arabic Speech Intelligibility in Noise Test for adults, Arabic Dichotic Digit Test [version II], Gap in Noise Test, Duration Pattern Test, and Arabic Memory Tests. No significant difference was found between the two study groups I and II, but the significant difference was found between the study groups and the control group in all central auditory test results. Statistically significant difference was found between the control group and study groups I and II regarding all memory tests. The highest percentage of abnormality was present in temporal resolution and selective auditory attention in both study groups. There was no significant statistical correlation between the number of attacks/month and central auditory test results. There was no significant statistical correlation between the frequency of attacks in VM patients and central auditory test results.

Conclusions: Patients with migraine and vestibular migraine had an inferior performance in all psychophysical central auditory tests when compared with control. Also, there was no significant difference between the 2 study groups regarding central auditory test results which may support that both migraine with and without dizziness have the same pathophysiology.
\end{abstract}

Keywords: Migraine, Central auditory processing, Memory, Attention, Auditory cortex

\section{Background}

Migraine is a common disabling primary headache disorder. It is an inherited neurovascular disorder that recurs in its typical form as disabling attacks of unilateral throbbing headache, worsened by movements and routine daily activities. It lasts from 4 to $72 \mathrm{~h}$ associated with nausea, vomiting, and increased sensitivity to light and sounds [1].

\footnotetext{
* Correspondence: tayseerhesham2005@gmail.com

${ }^{1}$ Audiology Unit, ENT Department, Faculty of medicine, Ain Shams University, Shorouk city, Compound Calimera, Villa $4 \backslash 7$ E, Cairo, Egypt

Full list of author information is available at the end of the article
}

In migraine without aura $[\mathrm{MoA}]$, headache is commonly unilateral and pulsating, may be associated with nausea and vomiting, and lasts for one or several days. While in migraine with aura [MA], headache is preceded by transient focal neurological symptoms such as photophobia and phonophobia. Most migraine attacks start in the brain, as suggested by the premonitory symptoms such as difficulty with speech and reading and sensory hypersensitivity that in many patients are highly predictive of the attack and also by nature of some typical migraine triggers such as stress, sleep deprivation, oversleeping, hunger, and prolonged sensory stimulation [2]. 
Clinical laboratory vestibular tests in migraine patients with or without dizziness showed a variety of abnormalities including both peripheral and central abnormalities [3]. Moreover, some videonystagmographic abnormalities (such as positional nystagmus, canal paresis, and directional preponderance) were reported in $55 \%$ of vestibular migraine [4].

Central auditory processing [CAP] refers to the efficiency and effectiveness by which the central nervous system [CNS] utilizes auditory information. Bellis et al. described central auditory processing disorders [CAPD] as an observed deficiency in one or more of the following auditory behaviors: sound localization and lateralization, auditory discrimination, auditory pattern recognition, temporal aspect of audition [resolution, masking, integration, ordering], auditory performance decrements with competing acoustic signals, and auditory performance decrements with degraded acoustic signals [5]. Previous research on migraine patients has reported abnormalities in the auditory brainstem response [ABR]. These results indicated impending auditory malfunction in migraine and disruption of central auditory processing mechanisms. This malfunction could be one of the mechanisms predisposing a migraine sufferer to the increase in sensitivity to sound resulting in phonophobia [6].

The possibility of auditory dysfunction with migraine is understudied. Few studies were done to explore the relationship between chronic migraine and auditory function. Some reported abnormalities in audiometry and auditory brainstem response [ABR], but in general, results are few and controversial. Moreover, the pathophysiology of temporary and permanent auditory manifestations associated with migraine is still incompletely delineated [7].

Agessi et al. demonstrated that migraine could be related to an impaired central auditory processing. As patients with migraine had poor performance in auditory gap detection and in the discrimination of short- vs long-duration pattern, which presented impairment in the physiological mechanism of temporal processing especially in temporal resolution and temporal ordering when compared with controls. So, this work was designed to explore the effect of migraine on different auditory processing abilities and to compare the findings in vestibular migraine vs classic migraine [8].

\section{Methods}

This study was a case-control observational study started in June 2018 and ended in January 2020.

\section{Subjects}

Study group

It consisted of 40 adult patients, 20 with migraine and 20 with vestibular migraine (VM) according to the International Classification of Headache Disorder ICHD-3 2018) [9]. Their age ranged from 18 to 60 years.

Inclusion criteria A) Study group 1 (migraine):

1. At least five attacks fulfilling criteria $B-D$

2. Headache attacks lasting 4-72 h (untreated or unsuccessfully treated)

3. Headache has at least two of the following four characteristics:

(a) Unilateral location

(b) Pulsating quality

(c) Moderate or severe pain intensity

(d) Aggravation by or causing avoidance of routine physical activity (e.g., walking or climbing stairs)

4. During headache at least one of the following:

(a) Nausea and/or vomiting

(b) Photophobia and phonophobia

5. Not better accounted for by another ICHD-3 diagnosis

All patients were recruited from headache and dizziness outpatient clinic at Ain Shams hospitals.

B) Study group 2 (VM):

1. At least five episodes fulfilling criteria $C$ and $D$

2. A current or past history of migraine without aura or migraine with aura

3. Vestibular symptoms of moderate or severe intensity, lasting between $5 \mathrm{~min}$ and $72 \mathrm{~h}$

4. At least half of the episodes are associated with at least one of the following three migrainous features:

(a) Headache with at least two of the following four characteristics:

- Unilateral location

- Pulsating quality

- Moderate or severe intensity

- Aggravation by routine physical activity

(b) Photophobia and phonophobia

(c) Visual aura

5. Not better accounted for by another ICHD-3 diagnosis or by another vestibular disorder

Patients were examined between the attack of headache or vertigo

\section{Exclusion criteria (in both study groups)}

1. Patients with other types of headache rather than migraine

2. Patients with other neurological disorders 
3. History of earache, discharge, or surgery

\section{Control group}

Consisted of 20 normal healthy adults with the same age range as the study group with the following:

- No history of migraine or other types of headache

- No history of other neurological disorders

- No history of earache, discharge, or surgery

\section{Equipment}

1. A double-walled sound-treated room I.A.C. model 1602

2. Two-channel audiometer, Interacoustics, model AC40 (Denmark)

3. Acoustic immittancemeter, MAICO, model MI34 (USA)

4. GSI 61, clinical audiometer (USA)

Test materials The following psychophysical central auditory tests for adults were used:

1. Arabic Speech in Noise Test [SPIN] [10]

2. Arabic Dichotic Digits Test version I and II [11]

3. Gap in Noise Test [GIN] [12]

4. Duration Pattern Test [DPT] verbal and humming [13]

5. Arabic Memory Tests [14]

Methods The patients were subjected to the following:

1. Full neuro otologic history including the following:

(a) Detailed history of migraine attacks including demographic data such as age, sex, and educational level any medical or psychiatric illness, family history of migraine, and previous migraine treatment

(b) Detailed personal history using the Arabic version of the questionnaire for CAPD in adults (developed by Tawfik and Shalaby, 2005)

(c) Detailed history of dizziness or vertigo if present

(d) Associated auditory symptoms as [tinnitus]

2. Measurement of educational level was determined as follows:

(a) Low: if the subject was illiterate or if the subject can read and write or had a primary school education.

(b) Middle: if the subject had a preparatory or a secondary school education.

(c) High: if the subject had a bachelor, master, $\mathrm{PhD}$, or MD degrees.

3. Otological examination
4. Basic audiological evaluation, including pure tone audiometry [air conduction and bone conduction], speech audiometry, and acoustic immittancemetry.

5. Vestibular assessment details were collected from the patients' reports in vestibular clinic.

6. Psychophysical central auditory tests.

All tests were performed with subjects seated in a sound-treated room. Subjects received instructions as regards the test performance and practice items prior to the administration of each test.

\section{Descriptive statistics}

- Mean, standard deviation $[ \pm \mathrm{SD}]$

- Minimum and maximum values [range] for numerical data

- Frequency and percentage of non-numerical data

Analytical statistics The normality of distribution parameters was evaluated by one-sample KolmogrovoSmirnov first, then for normal distribution, the following tests were used:

1. One-way ANOVA test was used to assess the statistical significance of the difference between more than two group means.

2. One-way ANOVA post hoc tests once have determined that differences exist among the means; post hoc range tests and pairwise multiple comparisons can determine which means differ. Range tests identify homogeneous subsets of the means that are not different from each other. Pairwise multiple comparisons test the difference between each pair of means and yield a matrix where asterisks indicate significantly different group means at an alpha level of 0.05 . The same letters show non-significant difference between SNRs, and different letters show a significant difference.

3. The independent-samples $t$ test was used to assess the statistical significance of the difference between the two study group means.

4. Pearson correlations were used to assess the strength of association between two quantitative variables. The correlation coefficient denoted symbolically $r$ defines the strength and direction of the linear relationship between two variables.

5. The chi-square test and Fisher exact test were used to compare the qualitative data between the different groups.

$P$-value: level of significance:

$-P>0.05:$ non-significant [NS]

$-P \leq 0.05$ : significant $[\mathrm{S}]$

$-P \leq 0.01$ : highly significant $[\mathrm{HS}]$ 
Results (Tables 1, 2, 3, and 4)

Peripheral hearing in the three groups

All patients have type A tympanograms reflecting normal middle ear functions.

\section{Videonystagmography results in the three groups (Table 5)}

Central auditory test results of the three groups (Tables 6, $7,8,9,10,11,12$, and 13)

\section{Discussion}

This study was conducted on a total number of 60 subjects, classified into study group $[n=40]$ and control group $[n=20]$. The study group was divided into migraine group [study group $1, n=20$ ] and vestibular migraine group [study group II, $n=20$ ]. The mean age of study group 1 was 34.8 years and that of study group II was 33.8 years (Table 1 ). This agreed with the data reported by Burstein et al. [15] who reported that the mean age of migraine patients in their study was 32 years. All the study group patients had normal peripheral hearing (Fig. 1).

Both study group 1 and study group II showed more affection in females than in males, which was also reported by Furman et al. [16] and Sohn [17]. The female gender predominance may be attributed to cyclical hormonal changes in women due to fluctuations in estrogen level that seems to trigger headaches in many women. Most women report headaches immediately before or during their menstrual periods, while others develop migraine during pregnancy or menopause [18-20].

As regards the educational level of participants in this study, migraine was common among middle followed by high educational level than low level (Table 2). Hamed et al. [21] found that migraine prevalence was significant among those with middle educational level and labor workers. Furthermore, Lipton et al. [22] and Jeff [23] reported higher migraine prevalence with low social class and educational levels as individuals with low and middle educational levels often have more physical exhausting occupations with more exposure to sunlight, glair, and extremes of temperature and more stressful life. Moreover, the three study groups were matched as regards age, gender, and educational level (Table 1).

There was no statistically significant difference between the two study groups regarding the duration of disease and the number of attacks (Table 2). Regarding the family history of migraine, $50 \%$ of patient had a positive family history of migraine in the migraine group (Table 4). This agreed with Olsen and Russell [24] who reported that heritability of migraine was estimated to be between 40 and $60 \%$. On the contrary, the VM group reported positive family history in $20 \%$ only. This agreed with Hazza et al. [25]; their study reported positive family history in only $16 \%$ of vestibular migraine patients.

Studying the headache nature in both study groups revealed that the pain was unilateral and throbbing in most patients (Table 3). This agreed also with Loder et al. [26], who reported that about two-thirds of their migraine patients have unilateral and throbbing headache. Most of the patients in our study reported that attacks were usually triggered by many factors such as lack of sleep, stress, riding transportation, fasting, and certain odor. Accordingly, the quality of their life either routine daily life or their work performance was severely affected in many patients in both groups (Table 4). This agreed with Hamed et al. [21] who studied the epidemiology of migraine in Upper Egypt. They reported that $65 \%$ of patients had severe attack that stopped their daily activities. Additionally, the most common auditory symptoms in the present study was phonophobia as $95 \%$ of the migraine group and $85 \%$ of the VM group were complaining of phonophobia (Table 4). This agreed with Alborzi et al. [27] who found that the most common migraine

Table 1 Age and gender distribution of both study groups and control group

\begin{tabular}{|c|c|c|c|c|c|c|c|c|c|}
\hline Age & & \multicolumn{2}{|c|}{ Group I } & \multicolumn{2}{|c|}{ Group ॥ } & \multicolumn{2}{|c|}{ Control group } & $F^{*}$ & $P$ value \\
\hline Mean & & \multicolumn{2}{|c|}{34.85} & \multicolumn{2}{|c|}{33.80} & \multicolumn{2}{|c|}{34.25} & 0.09 & 0.92 \\
\hline SD & & \multicolumn{2}{|c|}{8.70} & \multicolumn{2}{|c|}{7.41} & \multicolumn{2}{|c|}{7.52} & & \\
\hline \multirow[t]{3}{*}{ Range } & & \multicolumn{2}{|c|}{$18-55$} & \multicolumn{2}{|c|}{$21-43$} & \multicolumn{2}{|c|}{$22-50$} & & \\
\hline & & \multicolumn{2}{|c|}{ Group I } & \multicolumn{2}{|c|}{ Group II } & \multicolumn{2}{|c|}{ Control group } & $X^{2 * *}$ & $P$ value \\
\hline & & $N$ & $\%$ & $N$ & $\%$ & $N$ & $\%$ & & \\
\hline \multirow[t]{2}{*}{ Gender } & Male & 3 & $15.0 \%$ & 3 & $15.0 \%$ & 4 & $20.0 \%$ & 0.35 & 1.00 \\
\hline & Female & 17 & $85.0 \%$ & 17 & $85.0 \%$ & 16 & $80.0 \%$ & & \\
\hline \multirow[t]{3}{*}{ Education } & Low & 3 & $15 \%$ & 2 & $10 \%$ & 4 & $20 \%$ & 4.55 & 0.36 \\
\hline & Middle & 10 & $50 \%$ & 9 & $45 \%$ & 8 & $40 \%$ & & \\
\hline & High & 7 & $35 \%$ & 9 & $45 \%$ & 8 & $40 \%$ & & \\
\hline
\end{tabular}


Table 2 Medical history of study group 1 (migraine) and study group 2 (VM)

\begin{tabular}{|c|c|c|c|c|c|c|c|c|}
\hline & \multicolumn{3}{|c|}{ Study group I } & \multicolumn{3}{|c|}{ Study group II } & \multirow[t]{2}{*}{$t^{*}$} & \multirow{2}{*}{$\begin{array}{l}P \\
\text { value }\end{array}$} \\
\hline & Mean & SD & Range & Mean & SD & Range & & \\
\hline Duration of disease (years) & 9.20 & 6.38 & $1-25$ & 5.83 & 5.04 & $1-15$ & 1.86 & 0.07 NS \\
\hline Number of attacks/month & 12.10 & 5.33 & $5-25$ & 10.70 & 6.79 & $3-12$ & 0.73 & $0.47 \mathrm{NS}$ \\
\hline
\end{tabular}

*Student $t$ test

auditory symptoms is phonophobia. Usually, phonophobia comes in association with photophobia. In the present study, the same percentage of patients who had phonophobia in both groups also reported photophobia (Table 4). This agreed with Vingen et al. [28], who reported that the same number of patients who complained of phonophobia had associated photophobia. Accordingly, these similarities between phonophobia and photophobia in migraine provide evidence that both phenomena share a common pathophysiological mechanism.

The vestibular symptoms of vestibular migraine were quite variable. They included episodic true vertigo, positional vertigo, constant imbalance, movement-associated disequilibrium, and/or lightheadedness (Fig. 2). Symptoms occurred before the onset of headache, during headache, or during headache-free interval (Figs. 3 and 4). Similarly, Neuhauser et al. [29] also reported that all forms of dizziness can occur with migraine. They were examined by VNG; we found that $25 \%$ of patients did not show any VNG abnormalities. Positional nystagmus was the commonest finding and was recorded in almost $70 \%$ of subjects. Caloric hypofunction was very infrequent

Table 3 Headache history of study group 1 (migraine) and study group 2 (VM)

\begin{tabular}{|c|c|c|c|c|c|}
\hline & & \multicolumn{2}{|c|}{$\begin{array}{l}\text { Study } \\
\text { group I }\end{array}$} & \multicolumn{2}{|c|}{$\begin{array}{l}\text { Study } \\
\text { group II }\end{array}$} \\
\hline & & $N$ & $\%$ & $N$ & $\%$ \\
\hline \multirow{2}{*}{$\begin{array}{l}\text { Family history of similar } \\
\text { conditions }\end{array}$} & Negative & 10 & $50.0 \%$ & 16 & $80.0 \%$ \\
\hline & Positive & 10 & $50.0 \%$ & 4 & $20.0 \%$ \\
\hline \multirow[t]{2}{*}{ Attack duration } & Days & 8 & $40.0 \%$ & 6 & $30.0 \%$ \\
\hline & Hours & 12 & $60.0 \%$ & 14 & $70.0 \%$ \\
\hline \multirow[t]{3}{*}{ Severity of attack } & Mild & 0 & $0.0 \%$ & 0 & $0.0 \%$ \\
\hline & Moderate & 5 & $25.0 \%$ & 7 & $35.0 \%$ \\
\hline & Severe & 15 & $75.0 \%$ & 13 & $65.0 \%$ \\
\hline \multirow[t]{2}{*}{ Location of pain } & Unilateral & 14 & $70.0 \%$ & 15 & $75.0 \%$ \\
\hline & All the head & 6 & $30.0 \%$ & 5 & $25.0 \%$ \\
\hline \multirow[t]{3}{*}{ Character of pain } & Throbbing & 15 & $75.0 \%$ & 12 & $60.0 \%$ \\
\hline & Stabbing & 3 & $15.0 \%$ & 5 & $25.0 \%$ \\
\hline & Others & 2 & $10.0 \%$ & 3 & $15.0 \%$ \\
\hline \multirow[t]{2}{*}{ Trigger factors } & $\begin{array}{l}\text { No triggering } \\
\text { factors }\end{array}$ & 5 & $25.0 \%$ & 3 & $15.0 \%$ \\
\hline & Present & 15 & $75.0 \%$ & 17 & $85.0 \%$ \\
\hline
\end{tabular}

[5\%]. None of the subjects demonstrated oculomotor abnormalities (Table 5). Similarly, Hazzaa et al. [25] studied VNG in 98 patients with VM. VNG test results demonstrated positional nystagmus in almost $60 \%$ of subjects. Accordingly, our result support the hypothesis that the lesion in VM is peripheral lesion. This agreed with Hazza et al. [30] who hypothesized the predominance of peripheral vestibular pathway affection among VM patients, with the absence of central vestibular findings in the vestibular test battery.

This was also explained by Furman [16] who supported the theory that migraine induced vasospasm and subsequent decrease in regional blood flow to the inner ear via the internal auditory artery from the anterior inferior cerebellar artery [AICA]. This could cause transient ischemia, with subsequent transient or permanent peripheral vestibular dysfunction. Numerous studies have documented that migraine can lead to permanent auditory and vestibular deficits resulting from the repeated circulation problems and plasma extravasation during the attacks. Subsequently, in patients with longstanding repeated attacks of migraine, vestibular dysfunction of peripheral type is more vulnerable to occur.

Table 6 and Fig. 4 represented the results of the Central Auditory Processing Questionnaire. The most common complaint for both groups was problems in memory and attention followed by difficulty in

Table 4 Associated symptoms with headache

\begin{tabular}{|c|c|c|c|c|c|}
\hline & & \multicolumn{2}{|c|}{$\begin{array}{l}\text { Study } \\
\text { group I }\end{array}$} & \multicolumn{2}{|c|}{$\begin{array}{l}\text { Study } \\
\text { group II }\end{array}$} \\
\hline & & $N$ & $\%$ & $N$ & $\%$ \\
\hline \multirow[t]{2}{*}{ Photophobia } & Absent & 1 & $5.0 \%$ & 3 & $15.0 \%$ \\
\hline & Present & 19 & $95.0 \%$ & 17 & $85.0 \%$ \\
\hline \multirow[t]{2}{*}{ Phonophobia } & Absent & 1 & $5.0 \%$ & 3 & $15.0 \%$ \\
\hline & Present & 19 & $95.0 \%$ & 17 & $85.0 \%$ \\
\hline \multirow[t]{2}{*}{ Associated dizziness } & Absent & 20 & $100 \%$ & 0 & $0.0 \%$ \\
\hline & Present & 0 & $0.0 \%$ & 20 & $100.0 \%$ \\
\hline \multirow{3}{*}{$\begin{array}{l}\text { Memory and concentration } \\
\text { complaint }\end{array}$} & Mild & 1 & $5.0 \%$ & 2 & $10.0 \%$ \\
\hline & Moderate & 5 & $25.0 \%$ & 4 & $20.0 \%$ \\
\hline & Severe & 14 & $70.0 \%$ & 14 & $70.0 \%$ \\
\hline
\end{tabular}

Regarding phonophobia and photophobia, both were reported in $95 \%$ of cases in group 1 and less common (only 85\%) of cases in group 2 Regarding dizziness, it was reported in all cases of group 2 only Memory and concentration complaints were more common in severe cases of both study groups 
Table 5 VNG findings in VM patients

\begin{tabular}{llllll}
\hline \multirow{2}{*}{ Test } & \multicolumn{2}{l}{ Normal } & & & \multicolumn{2}{l}{ Abnormal } \\
\cline { 2 - 3 } & No. & $\%$ & & No. & $\%$ \\
\hline Oculomotor & 20 & $100 \%$ & & 0 & $0 \%$ \\
Spontaneous & 20 & $100 \%$ & & 0 & $0 \%$ \\
Positional & 6 & $30 \%$ & & 14 & $70 \%$ \\
Positioning & 20 & $100 \%$ & & 0 & $0 \%$ \\
Caloric & 19 & $95 \%$ & & 1 & $5 \%$
\end{tabular}

Abnormal VNG findings were recorded in $75 \%$. Positional nystagmus is the commonest and is found in $70 \%$ of patients, and only one patient had abnormal caloric response, while none of the patients had abnormal oculomotor tests findings

understanding speech in background noise. Central auditory processing test result in the control as well as in the study groups were shown in Tables 7 and 8 . They showed reduced scores of both study groups in comparison with the control group. The mean scores were below the ninety-five confidence limit of the control group denoting abnormal central auditory test results. Further analysis by comparing the three groups showed statistically significant difference in all central auditory test results between the two study groups and the control group. However, there was no significant difference between the migraine group and the vestibular migraine group. This agreed with Dash et al. [31] who stated that clinical symptoms and cochleovestibular findings in

Table 6 Number and percentage of the patient's complaints in Central Auditory Processing Questionnaire for adults in both study groups

\begin{tabular}{|c|c|c|c|c|}
\hline & \multicolumn{2}{|c|}{$\begin{array}{l}\text { Migraine } \\
\text { group }\end{array}$} & \multicolumn{2}{|c|}{$\begin{array}{l}\text { VM } \\
\text { group }\end{array}$} \\
\hline & $N$ & $\%$ & $N$ & $\%$ \\
\hline 1. Hearing problems & 0 & $0 \%$ & 0 & $0 \%$ \\
\hline 2. Diffculty in understanding speech in quiet & 0 & $0 \%$ & 0 & $0 \%$ \\
\hline 3. Difficulty in understanding speech in noise & 13 & $65 \%$ & 15 & $75 \%$ \\
\hline 4. Difficulty in dealing with others & 4 & $20 \%$ & 5 & $25 \%$ \\
\hline 5. Asking a lot to repeat speech & 8 & $40 \%$ & 10 & $50 \%$ \\
\hline 6. Lack of attention & 13 & $65 \%$ & 14 & $70 \%$ \\
\hline 7. Diffculty in sound localization & 1 & $5 \%$ & 2 & $10 \%$ \\
\hline 8. Memory problems & 15 & $75 \%$ & 17 & $85 \%$ \\
\hline 9. Diffculty in music appreciation & 1 & $5 \%$ & 2 & $10 \%$ \\
\hline 10. Other medical problems & 2 & $10 \%$ & 4 & $20 \%$ \\
\hline 11. Family history of similar conditions & 3 & $15 \%$ & 2 & $10 \%$ \\
\hline 12. Work problems & 8 & $40 \%$ & 10 & $50 \%$ \\
\hline 13. Family communication problem & 5 & $25 \%$ & 7 & $35 \%$ \\
\hline 14. Previous problems in education & 10 & $50 \%$ & 8 & $40 \%$ \\
\hline
\end{tabular}

The most common complaint for both groups was problems in memory and attention (especially in the VM group), followed by difficulty in understanding speech in background noise $(75 \%$ of the VM group and $65 \%$ of the migraine group). Also, about half of both groups complained of previous problems in education mostly were memory and concentration problems
Table 7 Central auditory processing test results of the three groups

\begin{tabular}{|c|c|c|c|c|c|c|c|c|}
\hline & \multicolumn{2}{|c|}{ Group I } & \multicolumn{2}{|c|}{ Group II } & \multicolumn{2}{|c|}{ Control group } & \multirow[t]{2}{*}{$F^{*}$} & \multirow{2}{*}{$\begin{array}{l}P \\
\text { value }\end{array}$} \\
\hline & Mean & $S D$ & Mean & $S D$ & Mean & $S D$ & & \\
\hline SPIN (\%) & 81.00 & 6.34 & 79.60 & 9.35 & 94.45 & 4.01 & 28.08 & $<0.00$ \\
\hline Lt SPIN (\%) & 81.60 & 7.27 & 79.60 & 7.21 & 95.00 & 4.83 & 32.79 & $<0.00$ \\
\hline Rt DD (\%) & 90.55 & 6.95 & 91.75 & 7.86 & 97.20 & 3.81 & 6.05 & 0.004 \\
\hline t DD (\%) & 81.65 & 10.14 & 85.70 & 9.10 & 95.60 & 3.75 & 15.49 & $<0.00$ \\
\hline $8+D P(0)$ & 79.25 & 8.52 & 76.00 & 8.50 & 95.75 & 3.35 & 5.21 & 0.01 \\
\hline DP (\%) & 80.50 & 7.94 & 74.50 & 8.43 & 96.25 & 3.93 & 5.83 & 0.01 \\
\hline & 8.00 & 1.45 & 8.80 & 1.99 & 5.35 & 1.04 & 27.38 & $<0.00$ \\
\hline
\end{tabular}

One-way ANOVA test $\left(F^{*}\right)$ showed statistically significant difference among the three groups. Further analysis of the ANOVA test results using the post hoc test revealed that no significant difference was found between the two study groups 1 and 2, but the significant difference was found between the study groups and the control group in all central auditory test results

*One-way ANOVA test

cases of migraine with and without vertigo revealed no statistically significant difference.

The SPIN test result showed the highest percent of abnormality in both study groups, $100 \%$ in study group II and $95 \%$ in study group I (Table 9). This abnormality was consistent with the results of the APD questionnaire as difficulty in understanding speech in background noise was a common complaint. It was found in $65 \%$ of study group I and $75 \%$ of study group II (Table 9 and Fig. 4). This finding proved that migraine patient had severely impaired speech discrimination in noise, with no difference between the two study groups (Table 9). This agreed with Hosein et al. [32] who reported that migraine patients without aura have difficulty in speech perception in background noise, and their signal noise ratio [SNR] loss in quick speech in noise [Q-SIN] test

Table 8 Correlations between memory test results in the three groups

\begin{tabular}{|c|c|c|c|c|c|c|c|c|c|}
\hline & & \multicolumn{2}{|c|}{ Group I } & \multicolumn{2}{|c|}{ Group II } & \multicolumn{2}{|c|}{$\begin{array}{l}\text { Control } \\
\text { group }\end{array}$} & \multirow[t]{2}{*}{$X^{2 *}$} & \multirow[t]{2}{*}{$\begin{array}{l}P \\
\text { value }\end{array}$} \\
\hline & & $N$ & $\%$ & $N$ & $\%$ & $N$ & $\%$ & & \\
\hline \multirow{2}{*}{$\begin{array}{l}\text { Recognition } \\
\text { memory }\end{array}$} & Normal & 5 & $25.0 \%$ & 5 & $25.0 \%$ & 19 & $95.0 \%$ & \multirow[t]{2}{*}{26.16} & \multirow{2}{*}{$\begin{array}{l}< \\
0.00\end{array}$} \\
\hline & Abnormal & 15 & $75.0 \%$ & 15 & $75.0 \%$ & 1 & $5.0 \%$ & & \\
\hline \multirow{4}{*}{$\begin{array}{l}\text { Memory for } \\
\text { content }\end{array}$} & 3.00 & 2 & $10.0 \%$ & 1 & $5.0 \%$ & 0 & $0.0 \%$ & \multirow{4}{*}{$\begin{array}{l}22.78 \\
F E\end{array}$} & \multirow{4}{*}{$\begin{array}{l}< \\
0.001\end{array}$} \\
\hline & 4.00 & 7 & $35.0 \%$ & 8 & $40.0 \%$ & 0 & $0.0 \%$ & & \\
\hline & 5.00 & 11 & $55.0 \%$ & 11 & $55.0 \%$ & 13 & $65.0 \%$ & & \\
\hline & 6.00 & 0 & $0.0 \%$ & 0 & $0.0 \%$ & 7 & $35.0 \%$ & & \\
\hline \multirow{4}{*}{$\begin{array}{l}\text { Memory for } \\
\text { sequence }\end{array}$} & 3.00 & 2 & $10.0 \%$ & 1 & $5.0 \%$ & 0 & $0.0 \%$ & \multirow{4}{*}{$\begin{array}{l}21.14 \\
F E\end{array}$} & \multirow{4}{*}{$\begin{array}{l}< \\
0.001\end{array}$} \\
\hline & 4.00 & 7 & $35.0 \%$ & 8 & $40.0 \%$ & 0 & $0.0 \%$ & & \\
\hline & 5.00 & 11 & $55.0 \%$ & 11 & $55.0 \%$ & 14 & $70.0 \%$ & & \\
\hline & 6.00 & 0 & $0.0 \%$ & 0 & $0.0 \%$ & 6 & $30.0 \%$ & & \\
\hline
\end{tabular}

Statistically significant difference was found between the control group and study groups 1 and 2 regarding all memory tests. The numbers 3, 4, and 5 are referred to the number of words the subject can remember it in both memory for content and memory for sequence tests

${ }^{*}$ Chi-square test 
Table 9 Comparison between study groups I and II regarding the number and percent of abnormality in central auditory processing tests

\begin{tabular}{|c|c|c|c|c|c|c|c|}
\hline & & \multicolumn{2}{|c|}{ Group I } & \multicolumn{2}{|c|}{ Group II } & \multirow[t]{2}{*}{$x^{2 *}$} & \multirow[t]{2}{*}{$P$ value } \\
\hline & & $N$ & $\%$ & $N$ & $\%$ & & \\
\hline Rt SPIN & Abnormal & 20 & $100.0 \%$ & 20 & $100.0 \%$ & 0 & 1.00 \\
\hline Lt SPIN & Abnormal & 18 & $90.0 \%$ & 20 & $100.0 \%$ & 2.11 & 0.49 \\
\hline Rt DD & Abnormal & 18 & $90.0 \%$ & 17 & $85.0 \%$ & 0.23 & 1.00 \\
\hline Lt DD & Abnormal & 19 & $95.0 \%$ & 17 & $85.0 \%$ & 1.11 & 0.61 \\
\hline Rt DP & Abnormal & 17 & $85.0 \%$ & 19 & $95.0 \%$ & 1.11 & 0.61 \\
\hline Lt DP & Abnormal & 17 & $85.0 \%$ & 19 & $95 \%$ & 1.11 & 0.61 \\
\hline GIN & Abnormal & 20 & $100 \%$ & 20 & $100 \%$ & 0 & 1.00 \\
\hline $\begin{array}{l}\text { Recognition } \\
\text { memory }\end{array}$ & Abnormal & 15 & $75 \%$ & 15 & $75 \%$ & 0 & 1.00 \\
\hline $\begin{array}{l}\text { Memory for } \\
\text { content }\end{array}$ & Abnormal & 9 & $45 \%$ & 9 & $45 \%$ & 0 & 1.00 \\
\hline $\begin{array}{l}\text { Memory for } \\
\text { sequence }\end{array}$ & Abnormal & 9 & $45 \%$ & 9 & $45 \%$ & 0 & 1.00 \\
\hline
\end{tabular}

*Significant at 0.05

showed an abnormal increase compared to the control group. This was attributed to the structural and functional changes including the presence of white matter lesions under the cortex and thickening of the cortical regions that have been confirmed by imaging studies in people with migraine.

Krishnamurti [33] proved that the SPIN test is a useful procedure with moderate sensitivity to a variety of central auditory nervous system [CANS] disorder at different levels in the brain. Accordingly, SPIN test results should be interpreted cautiously in association with other central auditory tests as it is non-localizing to the site of lesion.

Regarding the dichotic integration ability, the DDT was used. Our results showed abnormal scores in both ears with marked reduction in Lt ear scores in both groups (Table 7). This denoted affection of higher auditory pathways mostly at the cortical level. This agreed with Morlet et al. [34], who found that problems in dichotic integration during the nonverbal dichotic test [NVDT] and abnormal N1 peak related to attention in

Table 10 Mean, standard deviation (SD), range, and $t$ test of the duration pattern test (verbal vs humming) response in both study groups

\begin{tabular}{|c|c|c|c|c|c|c|c|c|}
\hline \multirow[t]{2}{*}{ DP test } & \multicolumn{3}{|c|}{ Verbal } & \multicolumn{3}{|c|}{ Humming } & \multirow[t]{2}{*}{$t^{*}$} & \multirow{2}{*}{$\begin{array}{l}P \\
\text { value }\end{array}$} \\
\hline & Mean & $S D$ & Range & Mean & $S D$ & Range & & \\
\hline Migraine & 81.75 & 15.32 & 50-100 & 91 & 6.81 & $75-100$ & 4.28 & $<0.05$ \\
\hline VM & 81.53 & 13.86 & 60-100 & 90.3 & 6.97 & $75-100$ & 4.63 & $<0.05$ \\
\hline
\end{tabular}

As shown in this table, there is a significant difference between Humming response and verbal response in the duration pattern tests in both classic migraine group and vestibular migraine group reflecting deficit in verbal labeling of the duration of tones not in the duration discrimination *Paired $t$ test
Table 11 Abilities affected in both study groups using number and percentage of abnormalities in all central auditory tests results

\begin{tabular}{lllll}
\hline Abilities & \multicolumn{2}{l}{ Study group I } & \multicolumn{2}{l}{ Study group II } \\
\cline { 2 - 3 } $\begin{array}{l}\text { affected } \\
\begin{array}{l}\text { No. of } \\
\text { abnormal } \\
\text { cases }\end{array}\end{array}$ & $\begin{array}{l}\text { \% of } \\
\text { abnormality }\end{array}$ & $\begin{array}{l}\text { No. of } \\
\text { abnormal } \\
\text { cases }\end{array}$ & $\begin{array}{l}\text { \% of } \\
\text { abnormality }\end{array}$ \\
\hline $\begin{array}{l}\text { Selective } \\
\text { attention } \\
\text { (SPIN) }\end{array}$ & 38 & $95 \%$ & 40 & $100 \%$ \\
$\begin{array}{l}\text { Dichotic } \\
\text { listening (DD) }\end{array}$ & 37 & $92.5 \%$ & 34 & $85 \%$ \\
$\begin{array}{l}\text { Auditory } \\
\text { memory }\end{array}$ & 33 & $55 \%$ & 37 & $61 \%$ \\
$\begin{array}{l}\text { Temporal } \\
\text { resolution } \\
\text { (GIN) }\end{array}$ & 20 & $100 \%$ & 20 & $100 \%$ \\
$\begin{array}{l}\text { Temporal } \\
\text { patterning } \\
\text { (DP) }\end{array}$ & 34 & & & \\
\hline
\end{tabular}

This table shows that the highest percentage of abnormality was present in temporal resolution and selective auditory attention in both study groups

the long latency response test were observed in people with migraine.

The Gap in Noise [GIN] Test in this study was used to evaluate the auditory temporal resolution ability at the cortical level of the brain. The results showed the highest percent of abnormality, $100 \%$ in both groups (Table 7). These results were consistent with the study

Table 12 Correlation between both duration of disease and number of attacks and central auditory processing tests in study group 1 (migraine group)

\begin{tabular}{lll}
\hline & $\boldsymbol{r}^{*}$ & $\boldsymbol{P}$ value \\
\hline Duration of disease & -0.18 & 0.44 \\
Rt SPIN (\%) & -0.21 & 0.37 \\
Lt SPIN (\%) & 0.05 & 0.82 \\
Rt DD (\%) & -0.06 & 0.80 \\
Lt DD (\%) & -0.05 & 0.83 \\
Rt DP (\%) & -0.07 & 0.78 \\
Lt DP (\%) & -0.06 & 0.81 \\
GIN & & \\
Number of attacks/month & 0.19 & 0.42 \\
Rt SPIN (\%) & -0.11 & 0.64 \\
Lt SPIN (\%) & -0.004 & 0.99 \\
Rt DD (\%) & 0.16 & 0.51 \\
Lt DD (\%) & -0.07 & 0.77 \\
Rt DP (\%) & -0.03 & 0.92 \\
Lt DP (\%) & 0.15 & 0.53 \\
GIN &
\end{tabular}

There is no statistically significant correlation between the number of attacks and the duration of the disease and central auditory test results

*Pearson's correlation 
Table 13 Correlation between both the duration of disease and the number of attacks and auditory processing tests in study group 2 (VM)

\begin{tabular}{lll}
\hline & $\boldsymbol{r}^{*}$ & $\boldsymbol{P}$ value \\
\hline Duration of disease & -0.14 & 0.56 \\
Rt SPIN (\%) & -0.39 & 0.09 \\
Lt SPIN (\%) & -0.36 & 0.12 \\
Rt DD (\%) & -0.45 & 0.05 \\
Lt DD (\%) & -0.49 & 0.03 \\
Rt DP (\%) & -0.55 & 0.01 \\
Lt DP (\%) & 0.40 & 0.09 \\
GIN & & \\
Number of attacks/month & -0.30 & 0.20 \\
Rt SPIN (\%) & -0.20 & 0.40 \\
Lt SPIN (\%) & -0.10 & 0.67 \\
Rt DD (\%) & -0.28 & 0.23 \\
Lt DD (\%) & -0.28 & 0.24 \\
Rt DP (\%) & -0.41 & 0.07 \\
Lt DP (\%) & 0.25 & 0.28 \\
GIN & & \\
\hline
\end{tabular}

*Significant at 0.05

People with long duration of vestibular migraine are more affected than others regarding left dichotic digit (LT DD) and right and left duration pattern tests (Rt DP, LT DP)

There is no statistically significant correlation between the duration of the disease and the number of attacks and central auditory test results

conducted by Agessi et al. [8] who observed that adults with migraine presented with impairment in the physiologic mechanism of temporal processing, especially in temporal resolution and temporal ordering when compared with controls. The difference in performance on the GIN Test between patients with migraine and the control group may denote a central auditory system dysfunction in migraine patients either with or without dizziness.

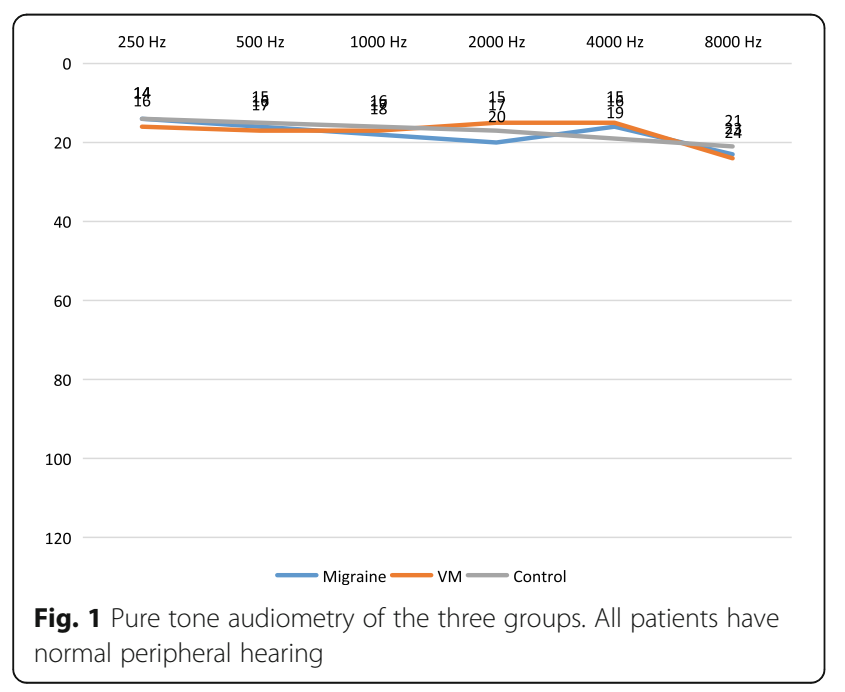

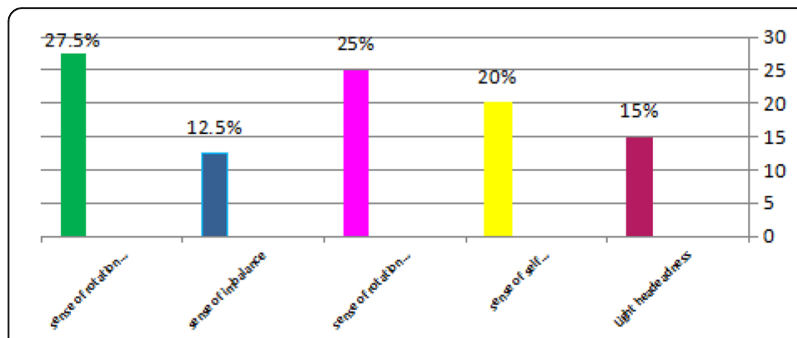

Fig. 2 Bar chart showing description of vertigo complaint in the VM group. This figure revealed that sense of self rotation with imbalance was the commonest type of the vertiginous attack

The DPT test results showed reduced scores in the two migraine groups when compared with control (Table 7 and Fig. 5). Furthermore, the mode of response to the duration pattern test was analyzed. It showed that the humming response was better than the verbal response in both groups (Table 10). This means that the response was hummed more correctly, denoting normal function of the right hemisphere. On the other hand, patients had difficulty reporting the response verbally denoting dysfunction either in the left hemisphere or interhemispheric pathways. There was no difference in performance between the two groups of migraine.

As regards memory test results, migraine patients showed impaired memory function in all tests including recognition memory, memory for content, and memory for sequence tests. This was consistent with Zeitlin and Oddy [35] who found that in a group of patients with severe migraine, they had significantly poorer performances in memory and information processing tests. These results were consistent with the APD questionnaire as memory and attention were frequently encountered complaints in the APD questionnaire in both groups (Table 6 and Fig. 4).

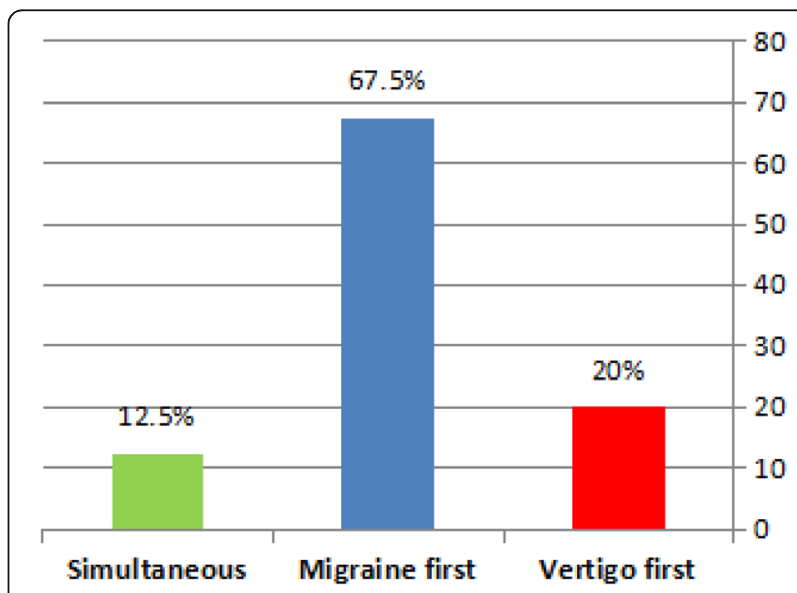

Fig. 3 Bar chart showing the temporal relationship of migraine and vertigo among VM patients. Most patients (more than two-thirds) suffered from migraine before vertigo 


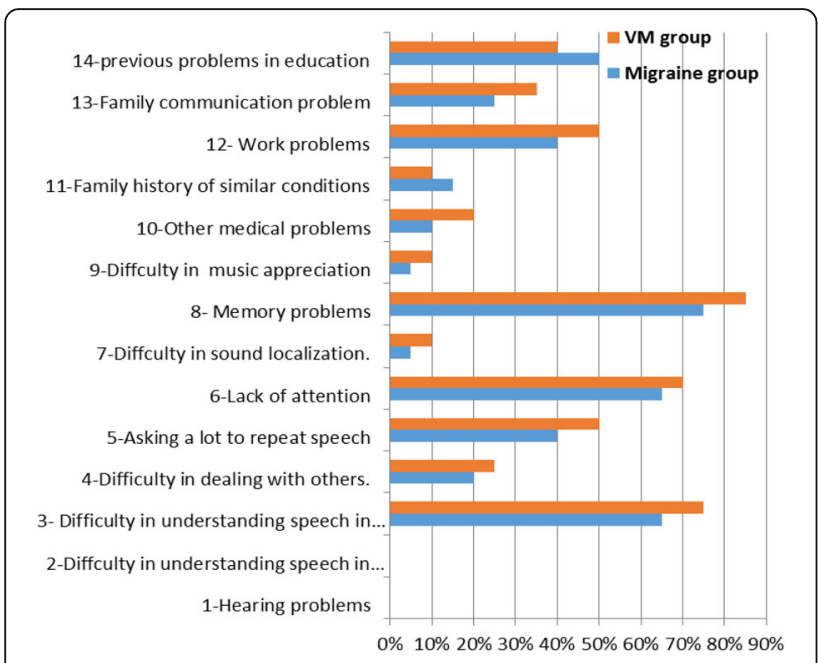

Fig. 4 Bar chart showing the percentage of patient complaints in the study groups using the Adult Central Auditory Processing Questionnaire. Memory and attention problems were the commonest complaint in both groups

Similarly, a systematic review by Barbosa et al. [36] studied 23 articles to evaluate cognitive impairment in migraine. They found that patients with migraine especially those followed at neurology clinics, often report cognitive complaints, especially regarding attention and memory. The most important cognitive functions include attention, short-term memory, and working memory. These cognitive activities act as compensatory mechanisms of the auditory system in cases of affected bottom-up processing such as lack of temporal encoding.

From all the previous results, we can hypothesize that migraine is triggered by a bottom-up mechanism from the brain stem up to the higher cortex. This agreed with

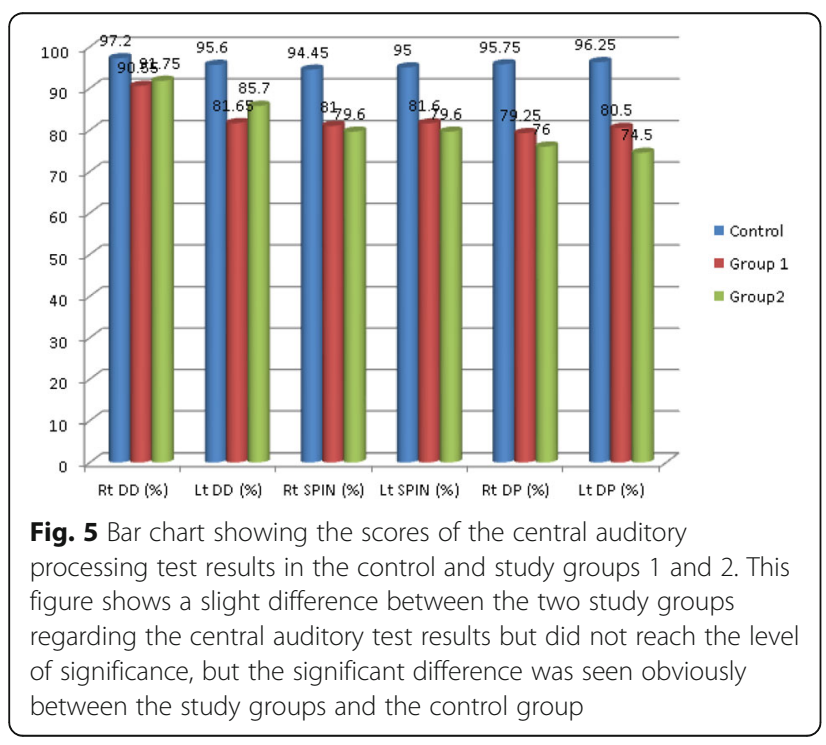

Borsook and Burstein [37]. They suggested that migraine was more than a headache. It was viewed as a complex neurological disorder that affects multiple cortical, subcortical, and brainstem areas which regulate autonomic, affective, cognitive, and sensory functions. As such, it was evident that the migraine brain differs from the non-migraine brain.

As shown in Table 11, temporal processing was the most frequently affected central auditory ability. All migraine patients in both groups had poor temporal resolution. While temporal patterning was affected in $85 \%$ group I and 95\% group II. The next affected ability was speech in noise discrimination and the least is dichotic listening. On the other hand, auditory memory abnormality was denoted in 55\% in group I and $61 \%$ in group II denoting less affection of top-down cognitive processing than bottom-up processing. The correlation studies that compared the duration of migraine, the frequency of attack, and the central auditory test results in study group I showed that there was no correlation (Tables 12 and 13). Similarly, Hosein et al. [32] found that migraine patients without aura have difficulty in speech perception in background noise, but there was no correlation between the duration of the disease or the frequency of attacks and [SNR] loss. Also, Bockowski et al. [38] on their study on cortical event-related potentials [CERP] in children with migraine headache found that no significant correlation between [CERP] parameters and duration of disease. This supported the recent theory that migraine occurs due to the release of neurogenic inflammation [NI] that is produced by the release of vasoactive pro-inflammatory neuropeptides from peripheral nerve endings such as calcitonin gene-related peptide [CGRP] and substance $P$ in several brain areas and not due to repeated ischemia caused by repeated attacks.

Regarding the vestibular migraine, there was no correlation between the number of attacks and the results of central auditory tests (Tables 12 and 13), but there was a negative correlation between the duration of disease and some of the central auditory test results. This may be related to the long presence of vestibular symptoms not to migraine duration itself. This agreed with Neuhauser et al. [29].

In addition, there was no difference in performance between vestibular and non-vestibular migraine. This may indicate that subclinical vestibular dysfunction is an integral part of migraine pathology in general and not only in vestibular migraine. Accordingly, it can be assumed that the a large overlap between migraine pathways and vestibular pathways and this is consistent with the view that vestibular migraine is a migraine variant with vestibular manifestations.

Finally, the present study showed that most patients with migraine-type headaches may experience changes 
in their auditory processing abilities through the different stages of a migraine attack, which may hinder their ability to complete tasks at work or home. This decrease in central auditory processing can impact the quality of life if not addressed and treated early. We recommend performing another longitudinal study to investigate the effect of different types of medical treatment on the central auditory processing of these patients. We expect an improvement of central auditory test scores, notably, the cognitive abilities.

\section{Limitations of this study}

Patients were receiving different types of migraine treatment and patients were suffering from different degrees of migraine. However, this heterogeneity did not affect the study results because most of the patients showed abnormal test scores, and the results were correlated to the duration and number of attacks.

\section{Conclusions}

Patients with migraine and vestibular migraine had an inferior performance in all psychophysical central auditory tests when compared with control. Also, there was no significant difference between the 2 study groups regarding central auditory test results which may support that both migraine with and without dizziness have the same pathophysiology.

\section{Acknowledgements}

None

\section{Authors' contributions}

ST: idea of research. RA: referral of patients. Sl: collection of data and analysis. TA: revision and references collection. All authors have read and approved the manuscript.

\section{Funding}

None

\section{Availability of data and materials}

The datasets generated during and/or analyzed during the current study are available.

\section{Declarations}

\section{Ethics approval and consent to participate}

Ethical committee of Ain Shams University No 2432.

Consent was obtained from the study participants before research; informed written consent is available.

\section{Consent for publication}

Not applicable.

\section{Competing interests}

The authors have no conflict of interest to declare.

\section{Author details}

${ }^{1}$ Audiology Unit, ENT Department, Faculty of medicine, Ain Shams University, Shorouk city, Compound Calimera, Villa 4\7 E, Cairo, Egypt. ${ }^{2}$ Neurology Department, Faculty of Medicine, Ain Shams University, Cairo, Egypt. ${ }^{3}$ Audiology Unit - ENT Department, Nasr City Insurance Hospital, Cairo, Egypt.
Received: 13 July 2021 Accepted: 24 September 2021

Published online: 20 November 2021

\section{References}

1. Bartleson J, Cutrer F (2010) Migraine update. Diagnosis and treatment. Minn Med 93:36-41

2. Hauge A, Kirchmann M, Olesen J (2011) Characterization of consistent triggers of migraine with aura. Cephalalgia 31(4):416-438. https://doi.org/1 $0.1177 / 0333102410382795$

3. Isizaki K, Mori N, Takeshima T (2002) Static stabilometry in patients with migraine and tension type headache during a headache free period. Psychiatry Clin Neurosci 56(1):25-90. https://doi.org/10.1046/j.1440-1819.2 002.00933.x

4. Kolkeila E, Elsanadiky H, Nour Y (2017) A study of the correlation between migraine and vestibular vertigo. Egypt J Ear, Nose, Throat Allied Sci 18(2): 95-101. https://doi.org/10.1016/j.ejenta.2016.09.001

5. Bellis T, Bellis J (2015) Central auditory processing disorders in children and adults. Handb Clin Neurol 139:537-556

6. Hamed S, Youssef A, Elattar A (2012) Assessment of cochlear and auditory pathways in patients with migraine. Am J Otolaryngol 33:385-394

7. Schoen J (2006) Neurophysiological features of the migrainous brain. Neurol Sci Suppl 2:77-81

8. Agessi M, Carvalho D, Villa T, Pereira L, Dias K (2014) Central auditory processing and migraine: a controlled study. J Headache Pain 15(1):1-72. https://doi.org/10.1186/1129-2377-15-72

9. Headache Classification Committee of the International Headache Society (IHS) (2018) The International Classification of Headache Disorders. Cephalalgia. 38(1):1-211. https://doi.org/10.1177/0333102417738202

10. Tawfik S, Shehata W, Shalabi A (1992) Development of Arabic speech intelligibility in noise (SPIN) test. Ain Shams Med J 3:677-682

11. Tawfik S, Weiheba H, Abdel-Maksoud A (2008) Standardization of two binaural dichotic digits and dichotic rhyme test on normal children. Master Thesis, Audiology Unit, ORL Department, Ain Shams University, Egypt

12. Musiek FE (1994) Frequency (pitch) and duration pattern tests. J Am Acad Audiol 5(4):265-268

13. Musiek FE, Shinn JB, Jirsa R, Bamiou DE, Baran JA, Zaida E (2006) GIN (GapsIn-Noise) test performance in subjects with confirmed central auditory nervous system involvement. Ear Hear 27(3):228 Ear Hear; 26(6): 608-618 (2005)

14. Tawfik S, Sadek I, Abdel-Maksoud A, Aboumussa H (2002) Assessment of auditory attention \& memory in scholastic under-achievers: psychophysical \& electrophysiological studies. Egypt J Otolaryngol 19(2):31-43

15. Burstein R, Noseda R, Borsook D (2015) Migraine: multiple process, complex pathophysiology. J Neurosci 35(17):6619-6629. https://doi.org/10.1523/ JNEUROSCI.0373-15.2015

16. Furman J (2003) Migrainous vertigo, development of a pathogenetic model and structured diagnostic interview. Neurology 16(1):5-13. https://doi.org/1 $0.1097 / 00019052-200302000-00002$

17. Sohn J (2016) Recent advance in the understanding of vestibular migraine. Behav Neurol 2016:1801845

18. Mehta S (2015) Study of various social and demographic variables associated with primary headache disorders in 500 school-going children of central India. J Pediatr Neurosci 10:13

19. Muller $L$ (2004) Diagnosis of common headache disorders in migraine in women. Migraine in women. BC Decker, Hamilton. Ontario, pp 17-35

20. Abdulkadr K, Arda L, Haydar S, Hava T, Hakki A (2005) Prevalence and characteristics of migraine in women of reproductive age in Istanbul, Turkey: a population-based survey. Tohoku J Exp Med. 206: $51-59$

21. Hamed SA, Kandil M, Abdel-Motagally K, Khalifa H, Mohamed K, Ghanem M (2016) Migraine in Assiut Governorate, Egypt: epidemiology, risk factors, comorbid conditions and predictors of change from episodic to chronic migraine. Neurol Res 38(3):232-241. https://doi.org/10.1080/01616412.201 5.1114232

22. Lipton R, Stewart W, Celentano D, Reed M (1992) Prevalence of migraine headache in the United States. Relation to age, income, race, and other sociodemographic factors. JAMA 267:64-69

23. Jeff $\cup$ (2006) Ahistorical prospective, a glimpse into the future and migraine epidemiology. Dis Mon. 52(10):367-384. https://doi.org/10.1016/.disa month.2006.09.002 
24. Olsen J, Russell M (1995) Increased familial risk and evidence generic factor in migraine. BMJ 311(7004):541-544. https://doi.org/10.1136/bmj.311.7004. 541

25. Hazzaa N, El-Mowafy S (2016) Clinical features of vestibular migraine in Egypt. Egypt J Ear, Nose, Throat Allied Sci 17(Issue 1):17-21

26. Loder E, Weizenbaum E, Giddon D (2018, Article ID 6157982) Migraine pain location and measures of healthcare use and distress: an observational study. Pain Res Manag Vol 2018:1-11. https://doi.org/10.1155/2018/6157982

27. Alborzi M, Zarrinkoob H, Dibajnia P, Tabatabaee S (2013) (Physiological and electrophysiological hearing tests in migrainers). Advances in. Cogn Sci. 15(1):59-66

28. Vingen J, Pareja J, Storen O, White L, Stovner L (1998) Phonophobia in migraine. Cephalalgia 18(5):243-249. https://doi.org/10.1046/j.1468-2982.1 998.1805243.x

29. Neuhauser HK, Radtke A, von Brevern M, Lezius F, Feldmann M, Lempert T (2009) Burden of dizziness and vertigo in the community. Arch Intern Med 169(1):89. Arch Intern Med; 168(19): 2118-2124

30. Hazzaa N, El Kabarity R, Gamil H (2018) Assessment of vestibular system functions in patients with vestibular migraine; (Un-published master thesis, Ain- Shams University)

31. Dash A, Panda N, Lal Khandelwal GV, Mann S (2008) Migraine and audio vestibular dysfunction; is there a correlation? Am J Otolaryngol Head Neck Med Surg 29(5):295-299

32. Hosein M, Amini S, Hajiabolhassan F, Fatahi J, Jalaie S (2018) Comparing the quick speech-in-noise test results in migraine patients without aura and normal subjects. Aud Vestib Res 27(4):215-222. https://doi.org/10.18502/avr. V27i4.127

33. Krishnamurti: Monural low -redundancy speech tests. Musiek F. \& Chermak J.; Handbook of central auditory processing disorder: volume I, Auditory Neuroscience and Diagnosis, ch. 8, pp. 193-205 (2007).

34. Morlet D, Demarquay G, Brudon F, Fischer C, Caclin A (2014) Attention orienting dysfunction with preserved automatic auditory change detection in migraine. Clin Neurophysiol 125(3):500-511

35. Zeitlin C, Oddy M (1984) Cognitive impairment in patients with severe migraine. Br J Clin Psychol 23(1):27-35. https://doi.org/10.1111/j.2044-8260.1 984.tb00623.x

36. Barbosa I, de Araújo C, Lemos S, Domingues R, Teixeira A (2012) Cognitive impairment in migraine: a systematic review. Dement Neuropsychol 6(2):7479. https://doi.org/10.1590/S1980-57642012DN06020002

37. Borsook D, Burstein R (2012) The enigma of the dorsolateral pons as a migraine generator. Cephalalgia. 32(11):803-812. https://doi.org/10.1177/ 0333102412453952

38. Boćkowski L, Sobaniec W, Sołowiej E, SmigielskaKuzia J (2004) Auditory cognitive event-related potentials in migraine with and without aura in children and adolescents. Neurol Neurochir Pol 38(1):9-14

\section{Publisher's Note}

Springer Nature remains neutral with regard to jurisdictional claims in published maps and institutional affiliations.

\section{Submit your manuscript to a SpringerOpen ${ }^{\circ}$ journal and benefit from:}

- Convenient online submission

- Rigorous peer review

- Open access: articles freely available online

- High visibility within the field

- Retaining the copyright to your article

Submit your next manuscript at $\boldsymbol{\nabla}$ springeropen.com 